\title{
Impending cardiac herniation following robotic mitral valve repair: A case report and review of the literature
}

\author{
Subbarao Elapavaluru, MD, ${ }^{\mathrm{a}, \mathrm{b}}$ Mary Matyi, MD, ${ }^{\mathrm{c}}$ Ray Crouch, MD, ${ }^{\mathrm{a}, \mathrm{b}}$ Amresh Raina, MD, FACC, ${ }^{\text {d,e }}$ and \\ Walter E. McGregor, MD, ${ }^{\text {,f }}$ Pittsburgh, $\mathrm{Pa}$
}

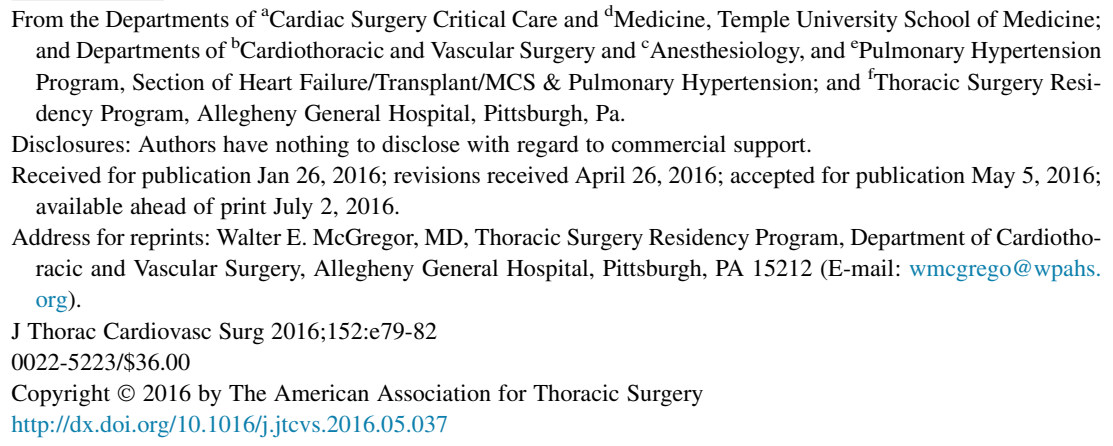

Video clip is available online.

A 48-year-old man with progressively symptomatic severe mitral insufficiency underwent minimally invasive right anterior thoracotomy, peripheral cannulation for cardiopulmonary bypass, and robot-assisted complex mitral valve repair with P2 triangular resection and 38-mm partial annuloplasty. Weaning from bypass was accomplished without inotropes, and transesophageal echocardiography revealed no residual mitral insufficiency and no evidence of systolic anterior motion. There was initial difficulty in ventilation of the right lung, which improved with manipulation of the double-lumen endotracheal tube. This was later exchanged to a single-lumen tube before transport to our cardiothoracic intensive care unit (CTICU), without difficulty. There was a perceptible, although initially noncritical, change in the patient's hemodynamic parameters upon transfer from the operating room table to the CTICU bed in the form of a mild drop in blood pressure and an increase in heart rate.

Following transfer to the CTICU, the patient remained intubated and was hemodynamically stable with a heart rate of 112 beats per minute, mean blood pressure of $76 \mathrm{~mm} \mathrm{Hg}$, central venous pressure of $12 \mathrm{~cm} \mathrm{H}_{2} \mathrm{O}$, mean pulmonary artery pressure of $20 \mathrm{~mm} \mathrm{Hg}$, and a cardiac index of $2.72 \mathrm{~L} / \mathrm{min} / \mathrm{m}^{2}$ in the absence of pharmacologic support. On physical examination at CTICU admission, a significantly displaced, large right paramedial impulse was noted. The pleural tube on the right side had no fluid drainage or air leak; the trachea was midline; and breath sounds were present, albeit diminished, on the right side.

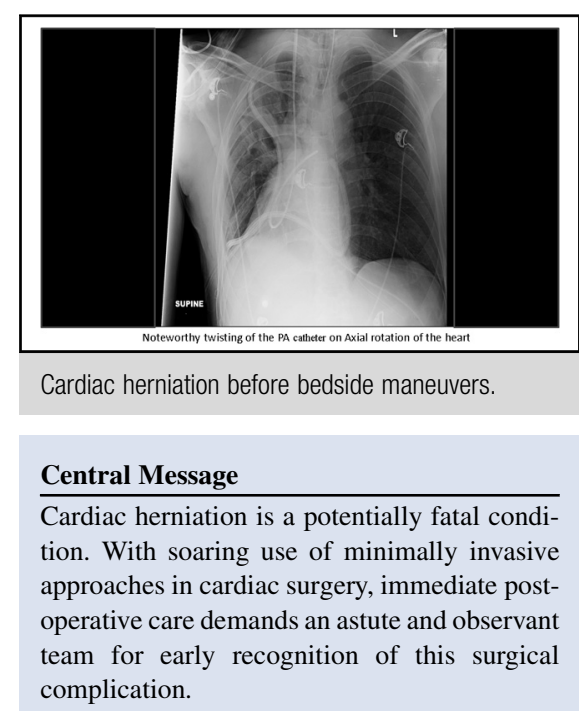

See Editorial Commentary page e83.

Arterial blood gas showed a $\mathrm{pH}$ of 7.36, carbon dioxide tension of $40 \mathrm{~mm} \mathrm{Hg}$, and oxygen tension of $86 \mathrm{~mm} \mathrm{Hg}$ on assist-control ventilation with the following parameters: respiratory rate of 12 breaths per minute, inspired oxygen fraction of $50 \%$, positive end-expiratory pressure of $5 \mathrm{~cm} \mathrm{H}_{2} \mathrm{O}$, and tidal volume of $500 \mathrm{cc}$. The history of difficult right lung reexpansion in the operating room and decreased breath sounds on physical examination in the CTICU prompted bronchoscopic evaluation that was unremarkable with patent central airways.

Postoperative chest radiograph (Figure 1) was markedly abnormal with rightward displacement of the cardiac contour and an abnormal course of the pulmonary artery catheter with an axial twist. The easily identifiable right parasternal impulse was suggestive of cardiac displacement and confirmed by the chest radiograph (Figure 1).

A nonoperative resolution in the CTICU was attempted because the patient continued to maintain a stable hemodynamic course, although we also arranged for a possible immediate return to the operating room. The patient was placed in the left lateral decubitus position, and suction was removed from the pleural tubes. We then administered large tidal volumes carefully with bag mask ventilation. Gentle percussion of the right chest was performed, resulting in a brief and self-limited episode of 

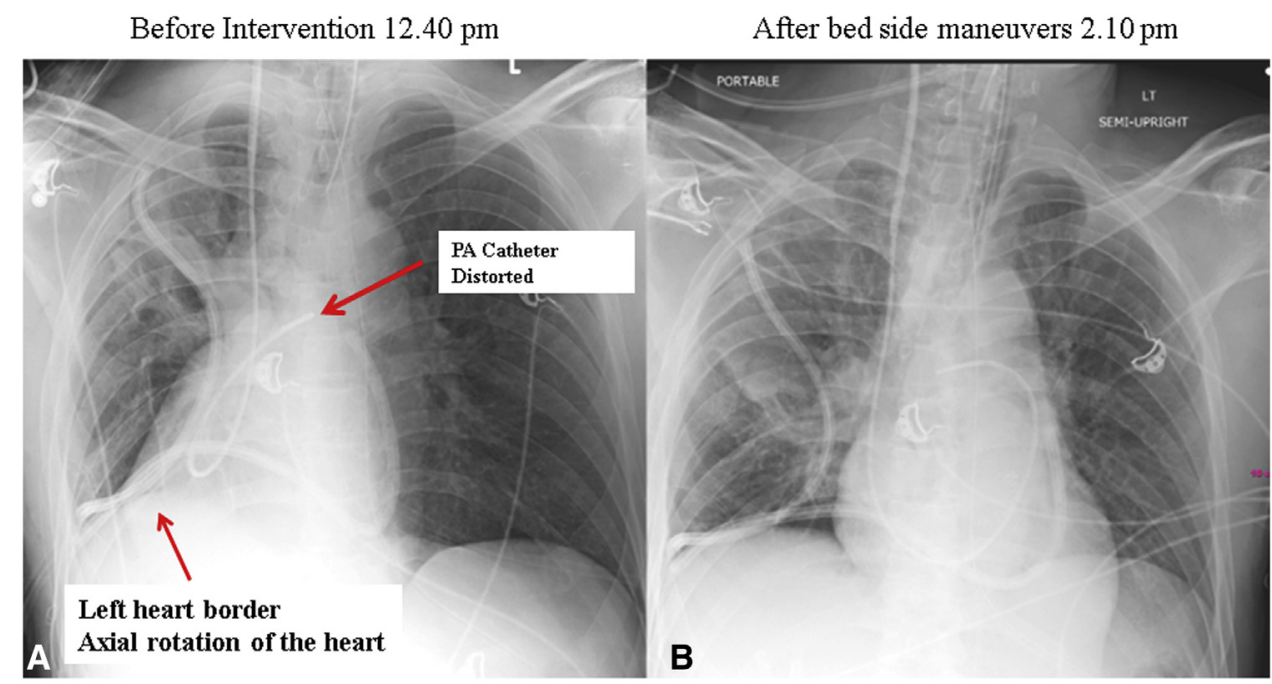

PA catheter and cardiac shadow restored after bed side maneuvers

FIGURE 1. Impending cardiac herniation (A) before and (B) after bedside maneuvers.

ventricular tachycardia followed by sinus tachycardia. Repeat chest radiograph (Figure 1) confirmed the return of the heart shadow to a normal position following intervention. The patient was discharged home 4 days later.

\section{DISCUSSION}

Cardiac herniation through a surgical or traumatic opening in the pericardium is a rare and potentially fatal condition and occurs following pneumonectomy or severe trauma. Morbidity and mortality may result from impeded venous return and to a lesser extent from focal coronary artery compression. Cardiac herniation immediately following left pneumonectomy was first reported by Bettman and Tannenbaum. ${ }^{1}$ The patient in question developed hemodynamic collapse following transfer from the operating room table to the CTICU bed. Moreover, acute or delayed cardiac herniation has occurred following blunt or penetrating chest trauma and pneumonectomy. ${ }^{2,3}$

Cardiac herniation as a complication of cardiac surgery has been less frequently documented and may develop secondary to sternotomy and wide pericardiotomy. The steady increase in minimally invasive and limited surgical approaches may contribute to the rarity of this complication. An exhaustive review of the medical literature yielded only 2 reports of cardiac herniation in the setting of minimally invasive cardiac surgery. ${ }^{4,5}$ In both instances each presented differently, and both recovered following surgical intervention. ${ }^{4,5} \mathrm{We}$ conducted an exhaustive literature review and have summarized all cardiac herniation case reports following cardiac surgical procedures (Table 1).

The relatively overventilated left lung could have contributed to the cardiac axial rotation and impending herniation (Video 1) in this case, either due to a mucus plug or migration of the double-lumen tube. Fortunately, the standard, small-sized pericardiotomy likely prevented this from actually occurring. We believe this case report's value is to increase awareness of cardiac complications that relate to double-lung ventilation. Furthermore, this report strongly emphasizes the seamless coordination between cardiac surgical and anesthesiology teams that is so critical to minimally invasive programs.

Since this case, our anesthesia team visually evaluates the double-lumen tube and airways once the crossclamp is removed and resumes ventilation of both lungs before weaning from cardiopulmonary bypass. We hope others can gain from our experience.

To our knowledge, ours is the first reported case of impending cardiac herniation following robotic mitral valve repair that was diagnosed at bedside in the CTICU by prompt and meticulous postoperative clinical examination and immediately relieved by bedside clinical maneuvers with an immediate reoperation as a backup strategy.

\section{CONCLUSIONS}

We describe a rare case of cardiac herniation after minimally invasive robotic mitral valve repair. This is the first adult case that was diagnosed and managed solely by bedside maneuvers. The interventions to treat impending cardiac herniation included left lateral decubitus positioning, aggressive positive pressure ventilation, removal of suction from pleural tubes, and gentle percussion, all with continuous clinical monitoring. Standard operative correction should be the mainstay of treatment of these cases with readiness for an immediate return to the 
TABLE 1. Case reports of cardiac herniation after cardiac surgery

\begin{tabular}{|c|c|c|c|c|c|c|c|}
\hline $\begin{array}{c}\text { First } \\
\text { author }\end{array}$ & $\begin{array}{c}\text { Journal } \\
\text { abbreviation }\end{array}$ & Year & Country & $\begin{array}{c}\text { Type of } \\
\text { cardiac surgery }\end{array}$ & $\begin{array}{l}\text { Presentations/ } \\
\text { complications }\end{array}$ & Outcomes & Diagnosis \\
\hline Mamoun $^{4}$ & AA Case Rep & 2013 & USA & $\begin{array}{l}\text { Minimally invasive } \\
\text { mitral valve surgery- } \\
\text { robot assisted }\end{array}$ & $\begin{array}{l}\text { 1. Mitral valvuloplasty: } \\
\text { (Duran ring) Unstable } \\
\text { while being moved to } \\
\text { the ICU from OR. } \\
\text { Promptly explored in } \\
\text { OR and pericardium } \\
\text { closed with } 3 \\
\text { interrupted sutures } \\
\text { 2. Robotically assisted, } \\
\text { minimally invasive } \\
\text { mitral valvuloplasty: } \\
\text { Asymptomatic did not } \\
\text { revert to left lateral } \\
\text { position. Taken back to } \\
\text { OR to close the } \\
\text { pericardial defect with } \\
\text { a synthetic patch }\end{array}$ & $\begin{array}{l}\text { 1. Survived, discharged } \\
\text { home } \\
\text { 2. Survived and } \\
\text { discharged home }\end{array}$ & $\begin{array}{l}\text { 1. TEE } \\
\text { 2. CXR }\end{array}$ \\
\hline Yamaguchi $^{5}$ & $\begin{array}{l}\text { J Thorac } \\
\text { Cardiovasc } \\
\text { Surg }\end{array}$ & 2012 & Japan & $\begin{array}{l}\text { Robot-assisted ASD } \\
\text { repair }\end{array}$ & $\begin{array}{l}\text { Intraoperative diagnosis } \\
\text { by TEE on } \\
\text { hypotension and rising } \\
\text { CVP } \\
\text { Patient was placed on left } \\
\text { side } \\
\text { No surgical repair of } \\
\text { pericardium } \\
\text { Was believed to be due to } \\
\text { strong positive } \\
\text { ventilation to the left } \\
\text { lung }\end{array}$ & Survived home in $2 \mathrm{~d}$ & TEE \\
\hline Speggiorin & Circulation & 2009 & Italy & $\begin{array}{c}\text { Minimally invasive repair } \\
\text { of PAPV drainage by } \\
\text { baffling into left atrium }\end{array}$ & $\begin{array}{l}\text { ICU CXR revealed } \\
\text { abnormal CXR and } \\
\text { was taken back to OR. } \\
\text { A redo thoracotomy } \\
\text { was performed and } \\
\text { heart replaced into } \\
\text { pericardial cavity and } \\
\text { pericardium closed by } \\
\text { PTFE membrane }\end{array}$ & Survived & Clinical suspicion CXR \\
\hline Wasir & Indian Heart $\mathbf{J}$ & 2006 & India & $\begin{array}{l}\text { ASD closure } \\
\text { Closure of sinus } \\
\text { venosus ASD }\end{array}$ & $\begin{array}{l}\text { Delayed } 14 \mathrm{~h} \text { from } \\
\text { presentation in the ICU } \\
\text { Diagnosed by CXR } \\
\text { Pericardial defect closed } \\
\text { by bovine patch } \\
\text { Right anterolateral } \\
\text { thoracotomy }\end{array}$ & Survived & CXR \\
\hline Wright & Thorax & 1970 & England & $\begin{array}{l}5 \text { cases: } 1 \text { congenital } \\
2 \text { traumatic } \\
2 \text { postoperative } \\
\text { ( } 1 \text { delayed presentation } \\
\text { after mitral valvotomy } \\
\text { for } \text { RHD) } \\
4 \text { noncardiac, } 1 \text { cardiac }\end{array}$ & $\begin{array}{l}\text { Delayed presentation } \\
\text { after } 3 \mathrm{y}\end{array}$ & Survival & $\begin{array}{l}\text { Clinical follow-up after } \\
3 \text { y and intraoperative } \\
\text { diagnosis redo } \\
\text { sternotomy }\end{array}$ \\
\hline
\end{tabular}

$\overline{I C U}$, Intensive care unit; $O R$, operating room; $T E E$, transesophageal echocardiography; $C X R$, chest radiograph; $A S D$, atrial septal defect; $C V P$, central venous pressure; $P A P V$, partial anomalous pulmonary vein; $P T F E$, polytetrafluoroethylene; $R H D$, rheumatic heart disease. 


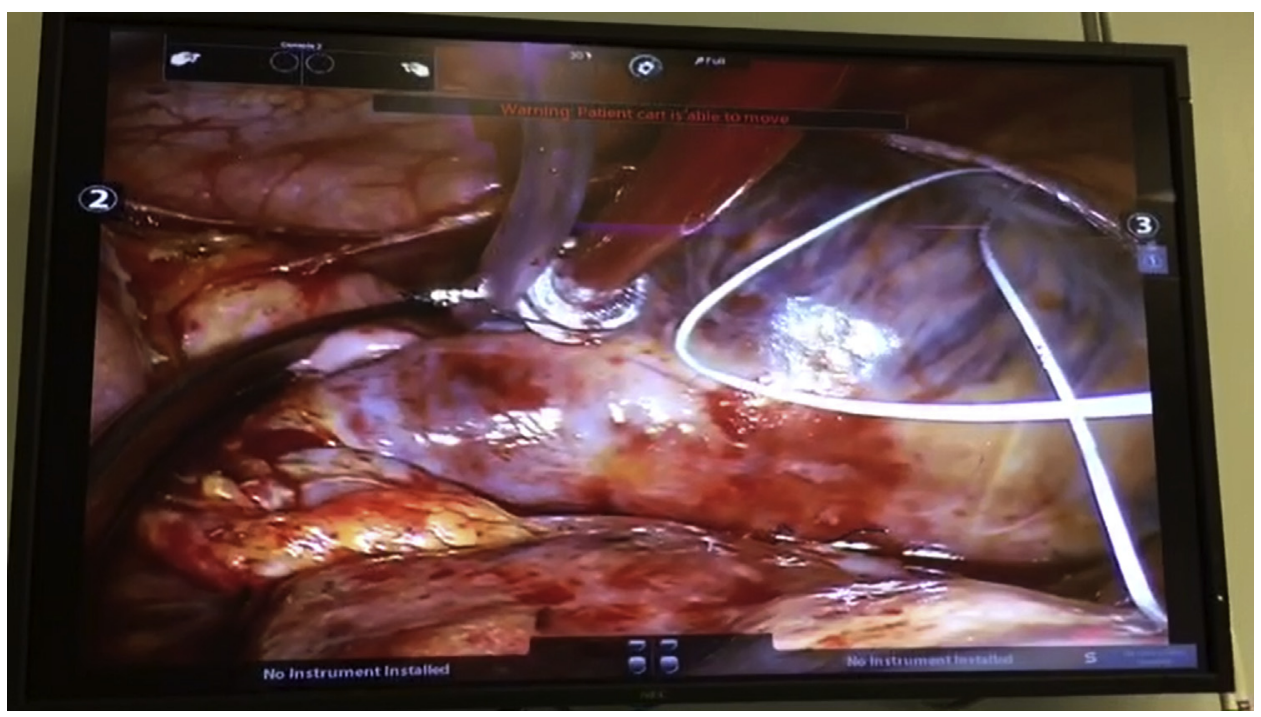

VIDEO 1. Note the exclusive left lung Valsalva and also the cardiac migration. We now provide a balanced lung ventilation as soon as possible after cardiopulmonary bypass.

operating room should noninvasive bedside maneuvers be unsuccessful. We confirm the absolute necessity of immediate, diligent, and knowledgeable personnel in the postoperative care of these cardiac surgery patients.

\section{References}

1. Bettman RB, Tannenbaum WJ. Herniation of the heart: through a pericardial incision. Ann Surg. 1948;128:1012-4.
2. Mehanna MJ, Israel GM, Katigbak M, Rubinowitz AN. Cardiac herniation after right pneumonectomy: case report and review of literature. J Thorac Imaging. 2007; $22: 280-2$

3. Sohn JH, Song JW, Seo JB, Do KH, Lee JS, Kim DK, et al. Case report: pericardial rupture and cardiac herniation after blunt trauma. A case diagnosed using cardiac MRI. Br J Radiol. 2005;78:447-9.

4. Mamoun NF, Koch CG, Gillinov AM. Cardiac herniation through a pericardial defect after minimally invasive mitral valve surgery. AA Case Rep. 2013;1:79-81.

5. Yamaguchi S, Ishikawa N, Watanbe G. Cardiac herniation during robot-assisted cardiac operation. J Thorac Cardiovasc Surg. 2012;143:e10-1. 